\title{
CoVID-19 Transforming postgraduate medical education during the COVID-19 pandemic: creating a trainee-led virtual teaching platform
}

\author{
Authors: Emma Collins, ${ }^{\mathrm{A}}$ Aminah Ahmad, ${ }^{\mathrm{B}}$ Hannah May, ${ }^{\mathrm{C}}$ Kathryn Price, ${ }^{\mathrm{D}}$ Elizabeth Egbase ${ }^{\mathrm{E}}$ and \\ Catherine Mathews ${ }^{\mathrm{F}}$
}

The COVID-19 pandemic has had a significant impact on the provision of postgraduate medical education across the country. There has been a widespread need to upskill and empower the medical workforce in order to tackle the evolving clinical situation. At Lewisham and Greenwich NHS Trust, traditional face-to-face group teaching was suspended due to the need for social distancing, but the appetite for learning was high. We recognised the need for alternative teaching methods and identified two key educational areas that required attention: topics related to COVID-19 and its management, and education for doctors being redeployed to other specialties. We developed an innovative method of education delivery to regularly provide high-quality, relevant material to hundreds of healthcare professionals at both hospital sites. We believe that our methods could help other organisations to maintain teaching as the pandemic progresses.

KEYWORDS: COVID-19, virtual teaching, postgraduate education, medical education

DOI: $10.7861 /$ fhj.2020-0062

\section{Introduction}

The COVID-19 pandemic has substantially impacted postgraduate medical education, as predicted by the GMC. ${ }^{\text {At At Lewisham }}$ and Greenwich NHS Trust (LGT), comprising University Hospital Lewisham (UHL, 450 beds) and Queen Elizabeth Hospital (QEH, 521 beds), face-to-face group teaching was discontinued in

Authors: ${ }^{A}$ CT3 ACCS anaesthetics, Lewisham and Greenwich NHS Trust, London, UK; ${ }^{B}$ CT1 ACCS anaesthetics, Lewisham and Greenwich NHS Trust, London, UK; ' medical education and leadership fellow, Lewisham and Greenwich NHS Trust, London, UK; DST3 geriatric medicine, Lewisham and Greenwich NHS Trust, London, UK; EST7 obstetrics and gynaecology, Lewisham and Greenwich NHS Trust, London, UK; Fdirector of medical education, Lewisham and Greenwich NHS Trust, London, UK
March 2020 in line with national social distancing advice. ${ }^{2}$ Meanwhile, service provision rapidly evolved during the COVID-19 pandemic to meet the increasing demand for acute medical and intensive care services. Work patterns and clinical roles of doctors changed dramatically, with many staff redeployed to frontline services in medicine, emergency medicine and critical care. Health Education England (HEE) recognises that these staff need adequate support and training to equip them in their new roles. ${ }^{3}$ A cross-specialty group of five trainees at LGT developed a novel platform with the aim of providing high quality educational material that was easily accessible, concise and delivered largely online. We wanted to encourage and facilitate educational opportunities during the pandemic, focusing on material relevant to treating patients with COVID-19. We also wanted to coordinate teaching efforts to avoid duplication. Here, we present our work to help other trusts improve education delivery at this challenging time.

\section{Methods}

We gained approval from the Trust medical director and director of medical education (DME) before starting, and the project was supervised by the DME and nominated consultants. We worked together to identify teaching topics, and to source and create resources. We used innovative methods of connectivity to distribute the resources, consistent with a framework of learning through communities of practice, with the shared domain of interest of treating COVID patients. ${ }^{4}$

A group was set up on the messaging platform WhatsApp in order to distribute educational material, and the joining link was shared with all LGT doctors. To maintain information governance, the identity of joining members was verified using their trust ID or email address. To comply with GDPR, no personal data were stored. Messages could only be sent by group administrators and followed a set, easy-to-read format (see supplementary material, S1). During the peak of the pandemic, guidelines were changing so frequently and appetite for learning was so high that we opted for one message each weekday. The daily message was composed of one or two posts about upcoming teaching or resources, a wellbeing resource and signed off with an inspirational "quote of the day'. An online document with links to material from previous messages was also distributed. A link to this document was 
emailed out to all LGT doctors to maintain accessibility to those not on WhatsApp.

We used four main teaching modalities: live webinars, pre-recorded videos, online resources, and practical skills sessions. Live webinars were hosted via teleconferencing software Zoom and mostly scheduled in the evening. They included medical teaching, interactive case presentations, and a peer support group, 'Sounding Circles'. The majority of medical teaching webinars were recorded with the presenter's permission, uploaded as an unlisted video to youtube. com and links sent out. Although confidentiality was maintained, we chose not to record case presentations. Practical skills sessions were the only face-to-face teaching and were ticketed via Eventbrite (www. eventbrite.co.uk) to keep groups small and allow social distancing.

The WhatsApp group and webinars provided a shared community, allowing sharing of information and experiences, with the daily messages and weekly webinars providing a shared practice, sustaining the interactions. In these ways, we felt this model fitted the educational theory of communities of practice. As well as this underpinning theory, we also sought regular feedback from participants to improve future sessions and tailor material. Electronic feedback forms were sent out after each session and a suggestions form for future topics was regularly advertised (see supplementary material, S2). As the most familiar method of feedback for traditional face-to-face teaching, survey methodology was chosen for this feedback too. We also contacted education leads and trainee representatives for further input.

\section{Outcomes}

In the first month, $414 \mathrm{LGT}$ doctors joined the WhatsApp group (around 600 junior doctors are employed by the Trust). Creation of a second group with identical content was necessary after the first one reached capacity at 256 members. We organised 29 teaching sessions: 15 webinars and 14 practical skills sessions, with a total of 512 live attendances and a mean of 30 attendees per webinar (Table 1). Our most popular event, with 67 attendees, was a webinar on respiratory physiology and ventilation delivered by an intensive care consultant. Five webinars were recorded for later viewing, which proved a popular addition to the programme. In the first month, these had 178 combined views and a total of 32 hours viewing time, but the mean view duration was only 10 minutes, or $22 \%$ of the video.

Over 30 other resources were sent out including written materials, links to relevant e-learning, videos, and PowerPoint presentations with recorded audio. Of these $29 \%$ were original or Trust resources and the remainder were from reputable external sources such as Health Education England, the British Medical Journal, Resuscitation Council or other hospital trusts. All were

\section{Table 1. Sessions held in the first month of the programme}

\begin{tabular}{|c|c|c|c|c|c|}
\hline Modality & Session details & Presenter & $\begin{array}{l}\text { Duration } \\
\text { (mins) }\end{array}$ & $\begin{array}{l}\text { Attendees } \\
\text { per session }\end{array}$ & $\begin{array}{l}\text { Number of } \\
\text { feedback forms } \\
\text { received }\end{array}$ \\
\hline \multirow[t]{6}{*}{$\begin{array}{l}\text { Webinar: } \\
\text { medical teaching }\end{array}$} & $\begin{array}{l}\text { Non-invasive ventilation } \\
\text { ( } 2 \text { sessions) }\end{array}$ & Respiratory consultant & 50 & 45 & 15 \\
\hline & $\begin{array}{l}\text { Diabetic ketoacidosis and } \\
\text { hyponatraemia }\end{array}$ & $\begin{array}{l}\text { Diabetes and endocrinology } \\
\text { consultant }\end{array}$ & 55 & 55 & 14 \\
\hline & $\begin{array}{l}\text { Respiratory physiology and } \\
\text { ventilation }\end{array}$ & ICM consultant & 80 & 67 & 6 \\
\hline & Human factors under pressure & O\&G ST7 & 60 & 8 & 1 \\
\hline & Acute kidney injury & Renal ST5 & 30 & 38 & 7 \\
\hline & $\begin{array}{l}\text { Whistle-stop ethics for the } \\
\text { pandemic }\end{array}$ & HIV consultant & 40 & 23 & 0 \\
\hline \multirow{4}{*}{$\begin{array}{l}\text { Webinar: } \\
\text { Case pesentation }\end{array}$} & COVID-19: breathless patient & O\&G and anaesthetics trainees & 45 & 50 & 4 \\
\hline & COVID-19: elderly patient & $\begin{array}{l}\text { Medical and anaesthetics } \\
\text { trainees }\end{array}$ & 45 & 47 & 10 \\
\hline & COVID-19: pregnant patient & O\&G ST7, anaesthetics ST3 & 45 & 25 & 4 \\
\hline & Medical: patient with headache & Medical ST3 and consultant & 60 & 23 & 3 \\
\hline $\begin{array}{l}\text { Webinar: } \\
\text { Sounding circles }\end{array}$ & Weekly ( 4 sessions) & O\&G ST7 & 60 & 6 & $\mathrm{n} / \mathrm{a}$ \\
\hline \multirow[t]{3}{*}{ Practical skills } & $\begin{array}{l}\text { Arterial line insertion } \\
\text { (10 sessions) }\end{array}$ & $\begin{array}{l}\text { Anaesthetics and ICM } \\
\text { trainees }\end{array}$ & 45 & 3 & 4 \\
\hline & $\begin{array}{l}\text { Thoracic ultrasound } \\
\text { ( } 2 \text { sessions) }\end{array}$ & $\begin{array}{l}\text { Emergency medicine } \\
\text { consultant }\end{array}$ & 60 & 10 & 6 \\
\hline & Ventilator settings ( 2 sessions) & $\begin{array}{l}\text { Anaesthetics CT2, ICM } \\
\text { consultant }\end{array}$ & 60 & 6 & 0 \\
\hline
\end{tabular}




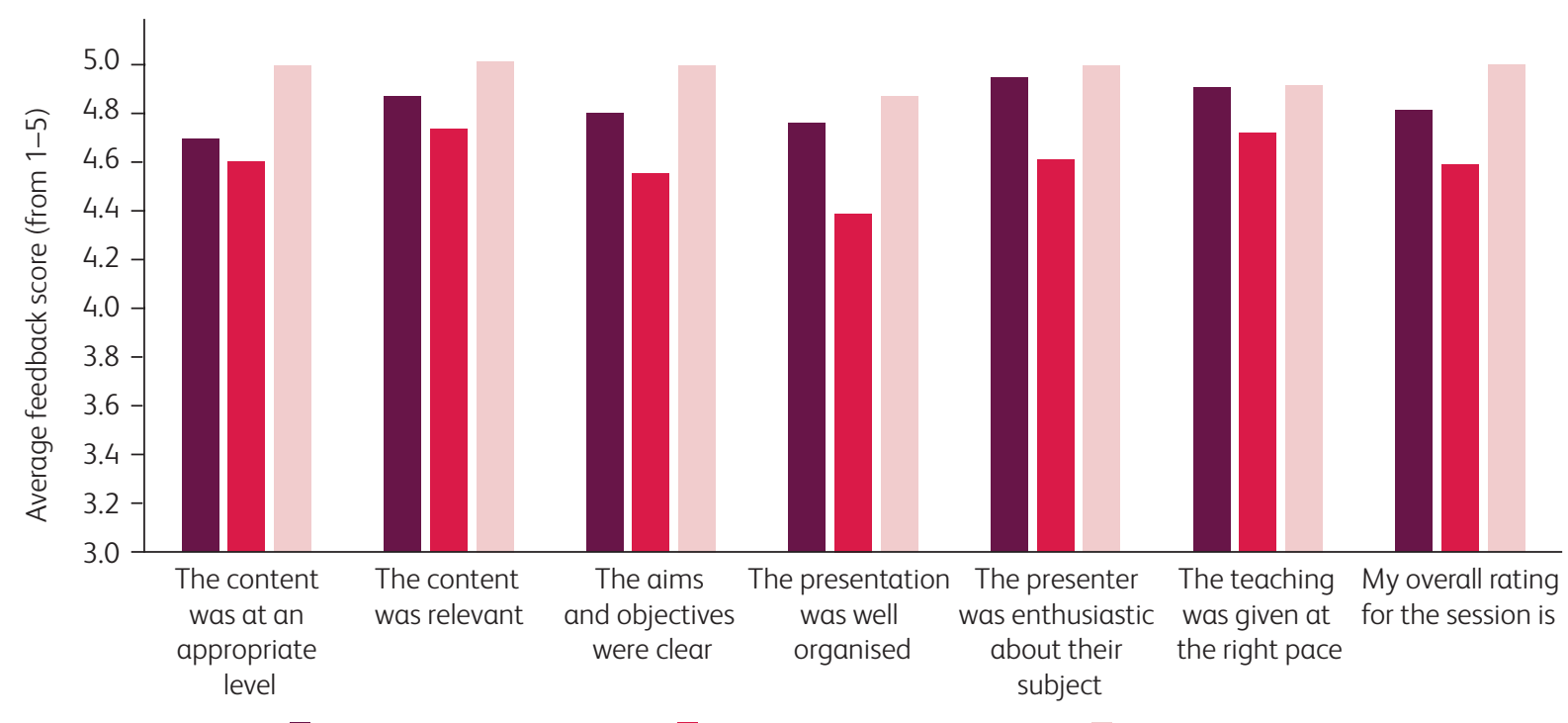

Webinar: medical teachina

Webinar: case presentation

Practical skills

Fig 1. Graph illustrating average feedback scores for each teaching modality.

approved by a consultant before distributing. Due to the nature of these resources (ie mostly external links), it was difficult to analyse engagement with these resources retrospectively.

\section{Feedback}

We asked attendees to rate sessions overall and in the following domains: content relevance, organisation and presenter quality (Fig 1). Engagement with feedback forms was low, with 74 completed forms received - an uptake rate of approximately 15\%. Respondents were from a variety of different specialties, with foundation, GP, medical and surgical trainees all represented. Feedback was very positive, with $79 \%$ of responders rating the session they attended $5 / 5$ overall. Practical skills sessions achieved the best feedback, with $100 \%$ of attendees rating them $5 / 5$. All sessions received positive feedback in response to the free-text questions (Fig 2).

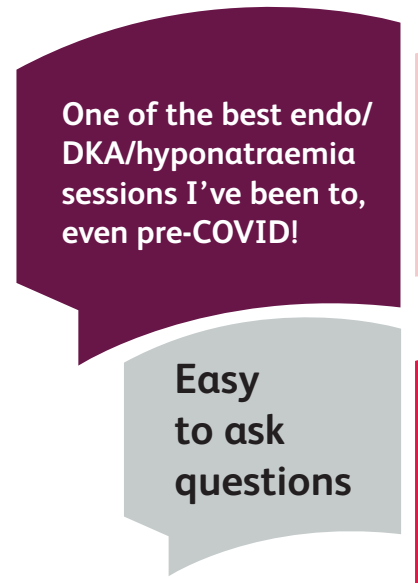

Great platform. Easy to use, I felt the platform worked well

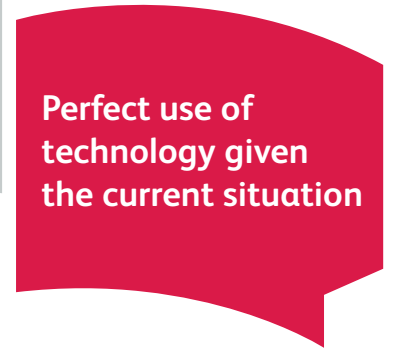

Fig 2. Examples of survey feedback to free-text questions.

\section{Discussion}

Enabling widespread, continued access to medical education for the doctors at LGT while maintaining social distancing during the COVID-19 pandemic presented a challenge. Yet we felt that providing access to accurate educational material was vital to help the workforce tackle the evolving clinical situation. We have described our successful, innovative, multimodal model for education which allowed us to provide relevant, accessible content that is easily adapted to meet demand.

This programme encouraged cross-specialty collaboration, with both attendees and presenters from a wide variety of specialties. Additionally, it enabled easy dissemination of wellbeing resources at a stressful time. WhatsApp proved a good platform for distribution at a time when email traffic was high, and made contact details of the organising team easily accessible. However, with any social media platform, security and data protection implications should be considered. By sending one concise message a day, we provided consistent access to content but tried to avoid information overload.

Feedback return rate was poor but may have been better had another modality been used such as webinar polls to collect realtime feedback. Although feedback seemed more positive for faceto-face than remote teaching, it is difficult to draw any conclusions from this owing to the very different nature of those sessions (face-to-face sessions evaluated were hands-on sessions in very small groups). It would be interesting to compare feedback from webinars to that of traditional face-to-face seminar-style teaching. Additionally, viewer retention was poor during webinar playback compared to the very high attendee retention during live webinars. Gegenfurtner and Ebner showed live webinars are indeed an effective method of promoting student achievement. ${ }^{5}$

We have had to tailor our content to a diverse audience, with members from different specialties and grades. It was not intended to replace specialty-specific curriculum teaching, but to focus on COVID-19 relevant material. This has inevitably led to a high proportion of medical topics, but it could be expanded to other areas. We have neither accredited our webinars for CPD 
points, nor kept registers to produce attendance certificates. These are areas for future improvement.

\section{Future work}

We hope that other trusts will consider similar methods to enable ongoing teaching as the pandemic progresses. Considering social distancing parameters will likely continue for some time, there may be a long-term paradigm shift in how medical education is delivered. There may be scope for using a similar model for ongoing specialty teaching. Our novel approach provides a template that could be expanded beyond topics related to COVID-19 and used to adapt the delivery of medical education in the future, both during and after the current pandemic.

\section{Acknowledgments}

The authors thank Archana Vasireddy for her contribution to the teaching programme.

\section{Supplementary material}

Additional supplementary material may be found in the online version of this article at www.rcpjournals.org/fhj:

S1 - Sample daily message

S2 - Format of feedback form

\section{References}

1 General Medical Council. Guidance regarding medical education and training supporting the COVID-19 response. GMC, 2020. www. gmc-uk.org/news/news-archive/guidance-regarding-medicaleducation-and-training-supporting-the-covid-19-response [Accessed 7 May 2020].

2 United Kingdom Cabinet Office. Staying at home and away from others (social distancing). Cabinet Office, 2020. Accessed online on 07/05/2020 at: www.gov.uk/government/publications/full-guidance-onstaying-at-home-and-away-from-others/full-guidance-on-staying-athome-and-away-from-others [Accessed 7 May 2020].

3 Health Education England. Guidance for COVID-19 healthcare education. HEE, 2020. www.hee.nhs.uk/sites/default/files/documents/ healthcare \% 20education \% 20quality \% 20visits \% 20statement.pdf [Accessed 7 May 2020].

4 Egan T, Jaye C. Communities of clinical practice: the social organization of clinical learning. Health 2009;13:107-25.

5 Gegenfurtner A, Ebner C. Webinars in higher education and professional training: a meta-analysis and systematic review of randomized controlled trials. Educ Res Rev 2019;28:100293.

Address for correspondence: Dr Catherine Mathews, director of medical education, Medical Education Department,

Lewisham Hospital, Lewisham High Street, London, SE13 6LH. Email: catherinemathews@nhs.net 